\title{
Aerosol absorption retrieval at ultraviolet wavelengths in a complex environment
}

\author{
Stelios Kazadzis ${ }^{1,2}$, Panagiotis Raptis $^{2}$, Natalia Kouremeti ${ }^{1}$, Vassilis Amiridis ${ }^{3}$, Antti Arola ${ }^{4}$, \\ Evangelos Gerasopoulos ${ }^{2}$, and Gregory L. Schuster ${ }^{5}$ \\ ${ }^{1}$ Physikalisch-Meteorologisches Observatorium Davos, World Radiation Center (PMOD/WRC), Dorfstrasse 33, \\ 7260 Davos Dorf, Switzerland \\ ${ }^{2}$ Institute of Environmental Research and Sustainable Development, National Observatory of Athens, Greece \\ ${ }^{3}$ Institute of Astronomy Astrophysics, Space Applications and Remote Sensing, National Observatory of Athens, Greece \\ ${ }^{4}$ Finnish Meteorological Institute, Kuopio Unit, Finland \\ ${ }^{5}$ NASA Langley Research Center, Hampton, VA, USA \\ Correspondence to: Stelios Kazadzis (stelios.kazadzis@pmodwrc.ch)
}

Received: 18 August 2016 - Published in Atmos. Meas. Tech. Discuss.: 26 August 2016

Revised: 27 November 2016 - Accepted: 28 November 2016 - Published: 13 December 2016

\begin{abstract}
We have used total and diffuse UV irradiance measurements from a multi-filter rotating shadow-band radiometer (UVMFR) in order to investigate aerosol absorption in the UV range for a 5-year period in Athens, Greece. This dataset was used as input to a radiative transfer model and the single scattering albedo (SSA) at 368 and $332 \mathrm{~nm}$ was calculated. Retrievals from a collocated CIMEL sun photometer were used to evaluate the products and study the absorption spectral behavior of retrieved SSA values. The UVMFR SSA, together with synchronous, CIMEL-derived retrievals of SSA at $440 \mathrm{~nm}$, had a mean of $0.90,0.87$ and 0.83 , with lowest values (higher absorption) encountered at the shorter wavelengths. In addition, noticeable diurnal variation of the SSA in all wavelengths is shown, with amplitudes up to 0.05 . Strong SSA wavelength dependence is revealed for cases of low Ångström exponents, accompanied by a SSA decrease with decreasing extinction optical depth, suggesting varying influence under different aerosol composition. However, part of this dependence for low aerosol optical depths is masked by the enhanced SSA retrieval uncertainty. Dust and brown carbon UV absorbing properties were also investigated to explain seasonal patterns.
\end{abstract}

\section{Introduction}

The role of aerosols, both natural and anthropogenic, is of high importance for regional and global climate change studies, as well as for pollution mitigation strategies (e.g., IPCC, 2013). However, a considerable amount of work still needs to be carried out in this field, as aerosols may have highly complex impact at local, regional and global climate scales. Furthermore, the components controlling aerosol forcing account for the largest uncertainties in relation to anthropogenic climate change (IPCC, 2013). A comprehensive review of the assessment of the aerosol direct effect, its state of play as well as current outstanding issues is provided by IPCC (2013) and Yu et al. (2006). Both studies emphasize that significant uncertainties in modeled single scattering albedo (SSA) retrievals constitute one of the largest single sources of uncertainty in current modeling estimates of aerosol climate forcing. SSA is the ratio of scattering to total extinction (scattering plus absorption), and it depends strongly on the chemical composition, size and mixing state of particles, as well as on relative humidity and wavelength. Comprehensive measurements are crucial to understand the aforementioned effects and to reduce SSA uncertainties, which in turn propagate into aerosol radiative forcing estimates. For example, for the same aerosol load (aerosol optical depth - AOD), the absorbing nature of aerosols can result to up to $50 \%$ decrease in the erythemal irradiance compared 
to only scattering aerosols (Bais et al., 2014). It should be noted that SSA calculated in this study differs from in situ SSA values retrieved from absorption and scattering measurements at a single altitude level (e.g., at the ground). Thus, the SSA measured by sun-photometric measurements links with the radiation attenuation from aerosols in the whole atmospheric column.

In the visible (VIS) and in the near-infrared (NIR) parts of the spectrum, advanced retrieval algorithms for microphysical aerosol properties have been developed in the framework of the Aerosol Robotic Network (AERONET) and the Skyradiometer Network (SKYNET; e.g., Dubovik and King, 2000; Nakajima et al., 1996). AERONET stations currently provide inversion-based column average SSA retrievals at the VIS and NIR wavelengths (i.e., 440, 670, 870, $1020 \mathrm{~nm}$ ). In addition, surface direct and diffuse irradiances have been previously used to derive spectral AOD and SSA at visible and ultraviolet (UV) wavelengths (King and Herman, 1979; King, 1979; Petters et al., 2003; Eck et al., 1998; Krotkov et al., 2005b; Bais et al., 2005; Goering et al., 2005; Taylor et al., 2008; Kudo et al., 2008; Corr et al., 2009). As AERONET does not provide any information about SSA at UV, only a few publications dealing with aerosol absorption at UV wavelengths can be found (e.g., Eck et al., 1998; Krotkov et al., 2005a; Bais et al., 2005; Corr et al., 2009). Unlike AERONET, the SKYNET sun photometers (manufactured by Prede Co. Ltd., Japan) are able to retrieve SSA at the UV wavelengths (Khatri et al., 2016, and references therein).

It is envisaged that improvement in the measurement accuracy and in the general understanding of aerosol absorption at UV (and immediate derivatives like the SSA) in various scientific applications will contribute significantly to improving the accuracy of UV-related radiation forcing estimates. For example, desert dust particles (Alfaro et al., 2004) and soot produced by fossil fuel burning as well as urban transportation all strongly absorb UV radiation. However, the optical properties of other potential UV absorbers like organic, nitrate and aromatic aerosols are still poorly known (Jackobson, 1999). Torres et al. (2007), in an overview study of OMI aerosol products, summarized the algorithmic techniques of SSA satellite retrieval at $388 \mathrm{~nm}$, which uses the spectral variability between 354 and $388 \mathrm{~nm}$, the $388 \mathrm{~nm}$ reflectance and a selection of the aerosol type. These retrievals were compared to AERONET SSA at $440 \mathrm{~nm}$ and a root mean square error of 0.03 was found (Jethva et al., 2014). MFRSR UV SSA retrievals of carbonaceous aerosols have also been carried out in the Amazon basin (Mok et al., 2016). They reported that brown carbon shows negligible absorption at VIS wavelengths, but significant absorption and strong spectral dependence at UV wavelengths.

Bergstrom et al. (2003) showed that spectra of aerosol SSA obtained in different campaigns around the world differed significantly from region to region, but in ways that could be ascribed to regional aerosol composition. Moreover, results from air, ground and laboratory studies, us- ing both radiometric and in situ techniques, show that the fractions of black carbon, organic matter and mineral dust in atmospheric aerosols play a role in the determination of the wavelength dependence of aerosol absorption (Russell et al., 2010). Jethva and Torres (2011) provided a satellitebased evidence of the spectral dependence of absorption of biomass-burning aerosols over South America, using nearUV measurements from the Ozone Monitoring Instrument OMI during 2005-2007. Barnard et al. (2008) and Corr et al. (2009), while investigating the variability of SSA in a field study in the Mexico City metropolitan area, found that SSA in the near-UV spectral range ( 300 to $400 \mathrm{~nm}$ ) is much lower compared to SSA at $500 \mathrm{~nm}$, indicative of enhanced absorption in the near-UV range. They suggested that absorption by elemental carbon, dust or gas alone could not account for this enhanced absorption, leaving the organic carbon component of the aerosol as the most likely absorber. Many other studies report that, in addition to dust, the absorbing organic carbon compounds can induce strong spectral absorption, increasing towards the shortest UV wavelengths. Sources of these lightabsorbing organic carbon compounds (often called brown carbon) are various, e.g., biomass burning (e.g., Kirchstetter et al., 2004), urban smoke (e.g., Liu et al., 2015) and biogenic emissions (e.g., Flores et al., 2014).

Corr et al. (2009) presented a review of studies estimating SSA at different wavelengths. For the visible part of the spectrum, two different approaches have been introduced. The first (Dubovik et al., 2002) uses sky radiance measurements in a matrix inversion technique to calculate various aerosol microphysical properties. This methodology has been widely applied within AERONET. The second (Eck et al., 2003; Kassianov et al., 2005) proposes the use of radiative transfer model (RTM) calculations, using as input measurements of AOD and the ratio of direct to diffuse irradiance at specific wavelengths. However, in the case of SSA calculations at UV wavelengths, enhanced measurement uncertainties, RTM input assumptions and interference from absorption by other gases $\left(\mathrm{O}_{3}, \mathrm{NO}_{2}\right)$ make the retrieval unsound. All reported results concerning UV SSA utilize RTM combined with total and diffuse relative irradiance measurements (Herman et al., 1975; King and Herman, 1979; King, 1979; Petters et al., 2003; Krotkov et al., 2005b; Corr et al., 2009; Bais et al., 2005) or absolute irradiance measurements (Kazadzis et al., 2010; Ialongo et al., 2010; Bais et al., 2005). The review by Corr et al. (2009) also presents the major differences in the results of simulations of the SSA arising from RTM input assumptions, measurement techniques and retrieved wavelengths. An additional problem is that previous studies have been dealing with short time periods, as relevant measurements were conducted during campaign-based experiments.

Moosmuller et al. (2012) showed that iron concentration in mineral dust aerosols is linked to lower SSA at $405 \mathrm{~nm}$ compared to $870 \mathrm{~nm}$, which could be a hint for the lowest SSA in the UV-VIS range during dust events. Medina et al. (2012) also found large variation in the UV range SSA 
in El Paso-Juarez, with lower values compared to the visible wavelengths, and showed that during heavily polluted days SSA can get as low as 0.53 at $368 \mathrm{~nm}$. Another effort was made in Belgium to calculate SSA at lower UV wavelengths, using Brewer (direct and global spectral irradiance at UV range) measurements, revealing lowest values but high uncertainty (Nikitidou et al., 2013). Recently, Schuster et al. (2016) tried to distinguish aerosol types by their optical properties and assumed that dust particles have higher absorption at UV wavelengths. They used imaginary refractive index spectral dependence to separate from black carbon and infer hematite and goethite in the coarse mode. They found that dust particles containing hematite are highly absorbing in the UV region.

The implications of all aforementioned gaps in knowledge are multitude, as UV solar radiation has a broad range of effects on life (UNEP, 2003; UNEP et al., 1998, 2007). It influences not only human beings (e.g., Diffey, 1991) but also plants and animals (e.g., Bornman and Teramura, 1993). Furthermore, it causes degradation of materials and functions as a driver of atmospheric chemistry. There are various studies linking changes of the UV radiation field with changes in the scattering and absorption of aerosols in the atmosphere (e.g., Zerefos et al., 2012; Balis et al., 2004; Reuder and Schwander, 1999; Krzyścin and Puchalski, 1998). Such changes can be comparable in magnitude to those caused by the decline in stratospheric ozone (Elminir, 2007; Reuder and Schwander, 1999; Krotkov et al., 1998). As an example, analysis of long-term UV time series at Thessaloniki, Greece, showed a reduction of $7 \%$ of AOD $(305 \mathrm{~nm})$ per decade, while at the same time the UV irradiance increased by $9 \%$ (after removing ozone column effect on it). This could only be explained by change in the absorption characteristics of aerosols in the area (Meleti et al., 2009). Moreover, UV variation induced by changes in aerosol optical properties directly affect tropospheric photochemistry, causing

- increases in regional $\mathrm{O}_{3}$ (10-20 ppb for Eastern USA) caused by increased UV levels due to the presence of non-absorbing aerosols (Dickerson et al., 1997) and

- decreases in regional $\mathrm{O}_{3}$ (up to $50 \mathrm{ppb}$ for Mexico City and for particular days) caused by strong UV reduction due to absorbing aerosols (Castro et al., 2001).

There are several more scientific issues that may be clarified with accurate knowledge of aerosol absorption properties.

\section{Aerosol effects on UV trends may enhance, reduce or reverse effects of stratospheric ozone change}

Future scenarios for simulations of global UV levels are based on ozone recovery, having as their sole input the predicted future decline in columnar ozone. Furthermore, simulations of the observed reduction of anthropogenic aerosols in the atmosphere of the US and Europe, during the course of the last decade (den Outer et al., 2005), included only cloud and AOD changes in the characterization of potential UV trends. In this regard, changes in the absorbing properties of aerosols on a global scale would have a large effect on the uncertainty budget in any of the above simulations (WMO, 2003). For example, a decrease in aerosol absorption properties accompanied by an AOD decrease in Europe could lead to a significant acceleration of the calculated ozone decline related to UV upward trends (Kazadzis et al., 2009; Zerefos et al., 2012).

\section{Satellite retrieval algorithms of the surface UV irradiance are directly affected by the presence of absorbing aerosols}

The discrepancies between ground-based UV measurements and satellite-derived (OMI, TOMS, GOME) data are directly related to aerosol absorption that is absent from current satellite retrieval algorithms (Tanskanen et al., 2007; Arola et al., 2005). It has been shown that enhanced aerosol UV absorption in urban areas can cause up to $30 \%$ overestimation in the satellite-retrieved UV radiation (Kazadzis et al., 2009).

\section{Uncertainty in commonly used atmospheric radiative transfer applications and codes}

Radiative transfer algorithms, calculating surface UV irradiance, lack accuracy due to large uncertainties in the input parameters (e.g., ozone levels, aerosol composition and surface albedo) used in model calculations. It is well established that the major input source of uncertainty in radiative-transfer model is aerosol absorption (e.g., Van Weele et al., 2000). In particular, the direct radiative effect of aerosols is very sensitive to mid-visible SSA. For example, a change in SSA from 0.9 to 0.8 can often alter the sign of the direct effect (Yu et al., 2006). Furthermore, availability and quality of observational SSA data are not the same as for AOD (Krotkov et al., 2005a). This is compounded by the lack of information on the vertical profile of aerosol optical properties, such as the SSA on a global scale. Only a few case studies have dealt with such measurements and these are limited to local scales (Müller et al., 1999).

In this work, we adopt a methodology for the calculation of the UV SSA, which is based on the idea of Krotkov et al. (2005a, b) and Corr et al. (2009). The methodology, together with the retrieval tools used and the technical assumptions, is presented in Sect. 2. The results from UV SSA measurements and their comparison with synchronous AERONET retrievals in the visible range are presented in Sect. 3. Finally, discussion of the observed diurnal SSA patterns in Athens, SSA wavelength dependency as well as concluding remarks is presented in Sect. 4. 


\section{Instrumentation and retrieval methodology}

\subsection{Instrumentation}

In this work we present calculations of the SSA at two independently retrieved UV wavelengths, 332 and $368 \mathrm{~nm}$, in Athens, Greece. The period of measurements is from July 2009 to May 2014. The ground-based Atmospheric Remote Sensing Station (ARSS) has been in continuous operation since February 2009 to monitor ground radiation levels and aerosol loadings over Athens (Amiridis et al., 2009). ARSS is located on the roof of the Biomedical Research Foundation of the Academy of Athens $\left(37.9^{\circ} \mathrm{N}, 23.0^{\circ} \mathrm{E} ; 130 \mathrm{~m}\right.$ a.s.l.; http://apcg.meteo.noa.gr/) and the campus is located near the city center, $10 \mathrm{~km}$ from the sea (Gerasopoulos et al., 2009). The horizon view is clear at $360^{\circ}$ viewing angle. ARSS is equipped with a CIMEL CE318-NEDPS9 sun photometer for the retrieval of AOD at eight wavelengths, in the range from 340 to $1640 \mathrm{~nm}$, including polarization measurements, as part of NASA's AERONET (http://aeronet.gsfc.nasa.gov). The technical specifications of the instrument are described in detail by Holben et al. (1998). ARSS is also equipped with an ultraviolet multi-filter rotating shadow-band radiometer (UVMFR) for radiation measurements in the UV spectral region (Harrison et al., 1994). UVMFR measures both total and diffuse irradiance at seven specified wavelengths (300, 305.5, $311.4,317.6,325.4,332.4$ and $368 \mathrm{~nm}$ ), with a $2 \mathrm{~nm}$ nominal full width at half maximum (FWHM) bandwidth. The manufacturing company (Yankee Environmental Systems, USA) has provided the instrument with angular, spectral and absolute response functions for each wavelength channel of the instrument, all measured at the National Institute of Standards and Technology (Fig. 1). For the analysis included in this work we assume that the effective wavelengths for each channel were stable during the whole period of operation. Measurement of the total and diffuse irradiances are recorded every $10 \mathrm{~s}$ and stored as $1 \mathrm{~min}$ averages along with a computation of the direct irradiance. Measurement data were angle-corrected, calibrated and analyzed using the YESDAS Manager software. The individually characterized cosine response supplied with each instrument was used to correct, in real time, for deviations from the ideal cosine response (Harrison et al., 1994). For this work, we have used measurements of the two aforementioned instruments in conjunction with RTM Libradtran (Mayer and Kylling, 2005).

\subsection{Retrieval methodology}

SSA is a key aerosol optical property and describes the portion of solar irradiance that is scattered from the main direct beam passing through the atmosphere. Changes in SSA influence mostly the diffuse radiation reaching the Earth's surface, while its effect on direct radiation can be considered negligible. SSA at a wavelength $\lambda$ provides the contribution of aerosol particle scattering relative to the total extinction

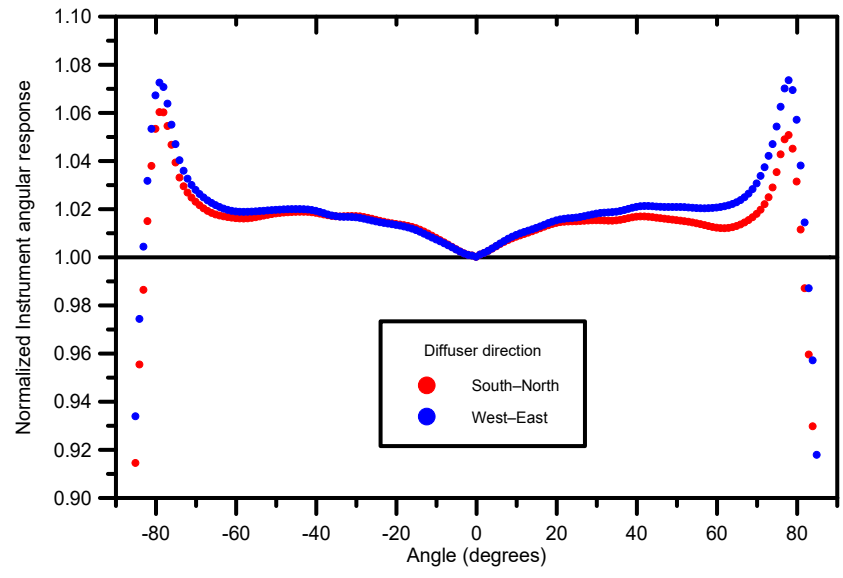

Figure 1. UVMFR angular response function at the $368 \mathrm{~nm}$ channel, normalized to the ideal (cosine) angular response. Two sets of responses, one from the south to north scan and one from the west to east, are provided.

(absorption plus scattering):

$\mathrm{SSA}=\frac{b_{\mathrm{sca}}(\lambda)}{b_{\mathrm{abs}}(\lambda)+b_{\mathrm{sca}}(\lambda)}$.

Theoretically, the SSA values range from 0 (totally absorbing aerosols) to 1 (totally scattering aerosol). However, actual SSA values in the atmosphere are found usually in the range from 0.65 to 1 (Corr et al., 2009). The asymmetry parameter is the phase function $(P)$ weighted average of the cosine of the scattering angle $(\theta)$, over all directions. Assuming azimuthal symmetry, the scattering angle integration extends from $-\pi$ to $+\pi$ such that the asymmetry parameter $(g)$ is given by

$g=\frac{1}{2} \cdot \int_{-\pi}^{\pi} \cos \theta \cdot P(\theta) \cdot \sin \theta \cdot \mathrm{d} \theta$.

Values for $\mathrm{g}$ range from -1 (backscattered radiation only) to 1 (forward scattered radiation only) in theory and from 0 to 1 for particles in the real atmosphere.

Model calculations can be used for retrieving SSA when global and/or diffuse spectral irradiance, solar zenith angle (SZA), total column ozone and AOD are known (Krotkov et al., 2005b; Kazadzis et al., 2010; Ialongo et al., 2010; Corr et al., 2009; Bais et al., 2005). In our retrieval methodology we have used partly the basic approach that is described in detail in Corr et al. (2009) and Krotkov et al. (2005a, b). This approach is based on measurements of the direct to global irradiance ratios (DGR) and AODs measured with the UVMFR instrument in our case, which are used as the basic input parameters to the RTM, for the calculation of the SSA at $332 \mathrm{~nm}$ and $368 \mathrm{~nm}$. These wavelengths are selected among the seven available due to their lowest ozone absorption (Paur and Bass, 1985). The advantage of this method is that the 
same detector and filter measure global and direct irradiance, thus there is no need for absolute irradiance calibration and raw voltage measurements (corrected for nighttime voltages and angular response) could be used.

Global irradiance measurements from the UVMFR have been used in order to distinguish cloud-free conditions for each of the $1 \mathrm{~min}$ measurements. Clouds are detectable in the measured UVMFR global irradiance (GI, at $368 \mathrm{~nm}$ ) since they cause larger variability than aerosols. To distinguish between cloudy and cloud-free conditions, we have applied an updated version of the method of Gröbner et al. (2001). The method is based on the comparison of the measured global irradiance with radiative transfer calculations for cloud-free conditions and quality assurance is checked with the following criteria:

a. The measured GI has to lie within the modeled (cloudfree) GI for a range of aerosol loads (AOD at $500 \mathrm{~nm}$ of 0.1 and 0.8 , respectively), corresponding to the 5th and 95th percentile of the AERONET data, for the examined location and period.

b. The rate of change in the measured GI with SZA has to be within the limits depicted by the modeled cloudfree GI, otherwise the measurements are assumed cloud contaminated.

c. All measured GI values within a time window ( $\mathrm{d} t= \pm 10 \mathrm{~min}$ ) should be within $5 \%$ of the modeled cloud-free GI and adjusted to the level of the measurement, using an integral over time interval.

If at least $85 \%$ of the points in the time window meet the criteria, then the central point is flagged as cloud free. In this study, we have allowed a tolerance level of $\pm 10 \%$ for tests (a) and (b) in order to compensate for differences between the modeled GI and measured GI due to instrumental uncertainties, as well as for the usage of average climatological parameters (constant total ozone column, SSA, etc.) as inputs to the model. We have limited the method to SZA $<70^{\circ}$ to avoid uncertainties related to low solar irradiance levels. An example of the results of the method is presented in Fig. 2 for a day with variable cloudiness. It has to be noted that in all CIMEL-UVMFR comparisons, using synchronous measurements, both the above method and AERONET cloud screening algorithm (presented by Smirnov, et al., 2000) are taken into account.

Measurements of the diffuse and global irradiance from the UVMFR were used to retrieve the direct irradiance at 332 and $368 \mathrm{~nm}$. We used the AERONET database to select days with very low AOD $(<0.1)$. For the urban environment of Athens, such cases are related to northerly winds. In the next step, we selected cloudless-sky half-days for determining extraterrestrial Langley calibration constant (ETC) by applying the Beer-Lambert law UVMFR direct voltage measurements. The $V_{\text {olangley }}$ in Fig. 3 represent the half-day values calculated with this method. In order to examine the consistency of this approach we calculated the $V_{0 \text { cimel }}$ also as

$V_{0 \text { cimel }}=V e^{\mu\left(\mathrm{AOD}_{\text {cimel }}+\tau_{\text {rayleigh }}\right)}$,

where $V$ is the voltage measured by UVMFR, $\mu$ is the air mass, $\mathrm{AOD}_{\text {cimel }}$ is the extrapolated AOD at UVMFR wavelengths and $\tau_{\text {rayleigh }}$ is the Rayleigh scattering optical depth. Daily averages of $V_{0 \text { cimel }}$ for the selected days were compared to $V_{0 l a n g l e y}$ as presented at Fig. 3. These independent approaches appear stable through the years, with no obvious drift or change, enabling use of a single ETC for the whole period for each wavelength.

AODs at 332 and $368 \mathrm{~nm}$ were calculated using the selected UVMFR derived ETC. In contrast to the Krotkov et al. (2005a) approach, we have not transferred the CIMEL ETCs to the UVMFR measurements; instead, we have independently calculated UVMFR-based AODs. Validation of the results was performed based on synchronous UVMFR and CIMEL measurements. The mean AOD calculated from the 1 min UVMFR measurements within \pm 5 min from the CIMEL measurement (when the UVMFR 10 min period is characterized by cloudless conditions) has been defined as synchronous. Since the CIMEL instrument provides measurements of AOD at 340 and $380 \mathrm{~nm}$, we first calculated the CIMEL derived AOD at 332 and $368 \mathrm{~nm}$, applying least square quadratic spectral extrapolation, using $\ln (\mathrm{AOD})$ as function of $\ln$ (wavelength) from AERONET measurements at 340 380, 440 and $500 \mathrm{~nm}$ (Eck et al., 1999).

This comparison turns out to have Pearson product moment correlation coefficient equal to 0.96 and 0.98 , respectively, for the 332 and $368 \mathrm{~nm}$ AODs. Mean differences were 0 , with standard deviations 0.031 and 0.025 for the respective wavelengths, comparable with the CIMEL AOD retrieval uncertainty $( \pm 0.02)$. The quality of the data produced can be verified by comparing the AODs retrieved by the two instruments as a function of SZA (Fig. 5). Relative stability of the AOD differences (that are in the order of the AERONET uncertainties) verifies the validity of the calibration of the UVMFR AODs. An AOD SZA-dependent trend, on the order of 0.02 (if excluding the $15^{\circ} \mathrm{SZA}$ bin) is observed, which could be attributed to the ETC determination uncertainty or to non-ideal correction for the cosine response error of the UVMFR.

In Fig. 5, AOD values were grouped into bins of $5^{\circ}$ (of SZA). The differences shown in Fig. 5 include the ETC determination accuracy, the extrapolation of CIMEL AOD at $368 \mathrm{~nm}$ and instrumental/measurement errors. Using a single UVMFR ETC for the whole period provides very good agreement between the two instruments. However, this may not be the case for all UVMFR instruments using this approach, as ETC may suddenly or gradually change, especially for year-long time series, due to instrumental (filterrelated) changes. AOD deviations could lead to large errors in SSA calculations, so this comparison ensures that these errors are minimized. The instrument's teflon diffuser contam- 


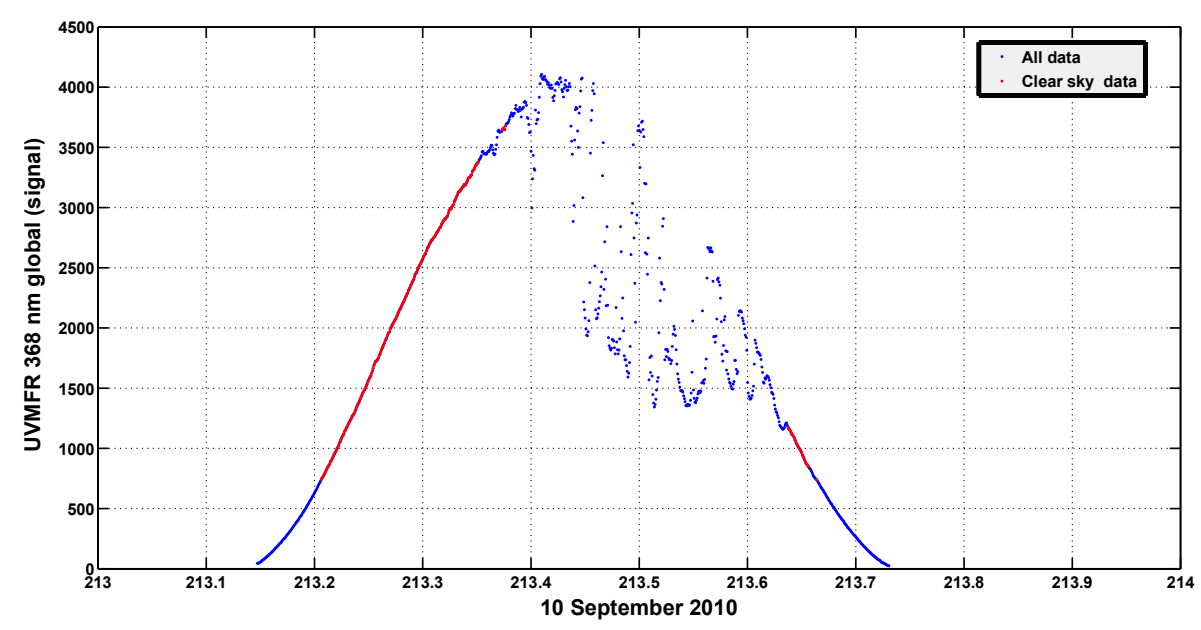

Figure 2. Determination of cloudless 1 min measurements (red), from all measurements (blue) for a day with variable cloudiness in the afternoon.

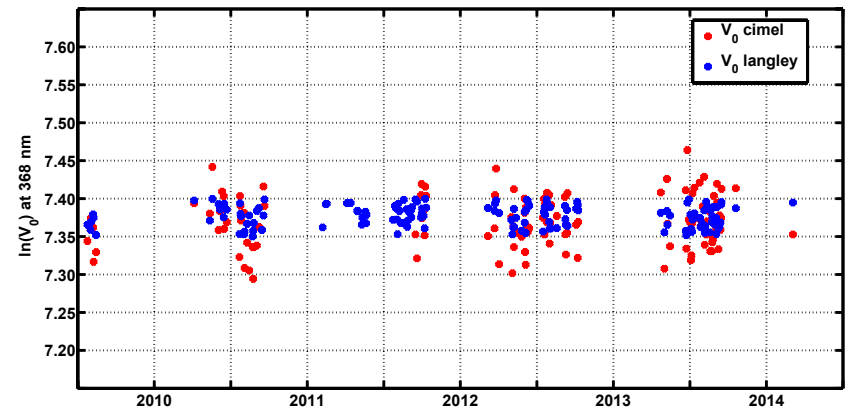

Figure 3. ETC values at $368 \mathrm{~nm}$, calculated using Langley plots of UVMFR measurements and using Cimel extrapolated AODs as input, for selected (low AODs and clear sky) days for the whole period.

ination is the most common reason for long-term changes in the ETC. The maintenance procedure for the instrument operating in Athens included cleaning and inspection of the diffuser and checking of the leveling and shadowing three times a week. In addition, metal spikes were built around the instrument to avoid the diffuser destruction by birds.

Applying the RTM, we calculated look-up tables (LUT) of the DGR values at 368 and $332 \mathrm{~nm}$ as a function of SZA, AOD, SSA, asymmetry factor $(g)$ and the total column ozone. CIMEL-AERONET mean daily ozone values and climatological - satellite-derived $-\mathrm{NO}_{2}$ values, were used for the construction of the LUT. For g, we used the mean daily value as retrieved at $440 \mathrm{~nm}$ from the CIMEL measurements, when available, and the mean value of the whole period was equal to 0.7 ( $2 \sigma$ standard deviation of the $\mathrm{g}$ during this period was 0.04). Using the UVMFR AOD and DGR measurements, we then calculated the matching SSA values for each individual UVMFR DGR measurement. LUT examples are visualized in Fig. 6. For known SZA and AOD (in cloudless-sky conditions), the variability of the DGR is caused by aerosol properties other than AOD. At low aerosol loads this variation is nearly negligible, but it becomes more important at higher aerosol loads. More absorbing aerosols result in smaller values of DGR. It is crucial to observe the range of SSAs in the two examples. For low AODs, accurate SSA determination requires very low uncertainty of the DGR and the AOD measurement, while for high AODs the range of DGRs, for a particular SZA, is quite large.

\subsection{Retrieval uncertainties}

The CIMEL sun photometer provides SSA inversion retrievals labeled as Level 1.5 and Level 2.0 data. Level 2.0 (L2) data are recommended by AERONET as they have less uncertainty but they are restricted to measurement with $\mathrm{SZA}>50^{\circ}$, AOD (at $440 \mathrm{~nm}$ ) $>0.4$ and homogeneous sky conditions. These limitations make AERONET SSA L2 worldwide measurements unsuitable for the following:

a. Climatological studies at areas without large average annual AODs or cases of moderate to high aerosol episodes: as an example, for the urban site of Athens the number of measurements is limited to an average of 11 cases per month, for the whole analysis period.

b. Diurnal variation studies due to the SZA restriction. For mid- and low-latitude sites, this limitation leads to a crucial lack of information on diurnal SSA patterns, as there are only few wintertime measurements and close to zero measurements at local noon.

AERONET Level 1.5 (L1.5) SSA data are provided by AERONET for all AODs and at all SZA that almucantar scans are performed. In this work L1.5 data were used with an extra quality control. We have ignored SSA L1.5 data when L2 size distribution is not available. Thus, we have 

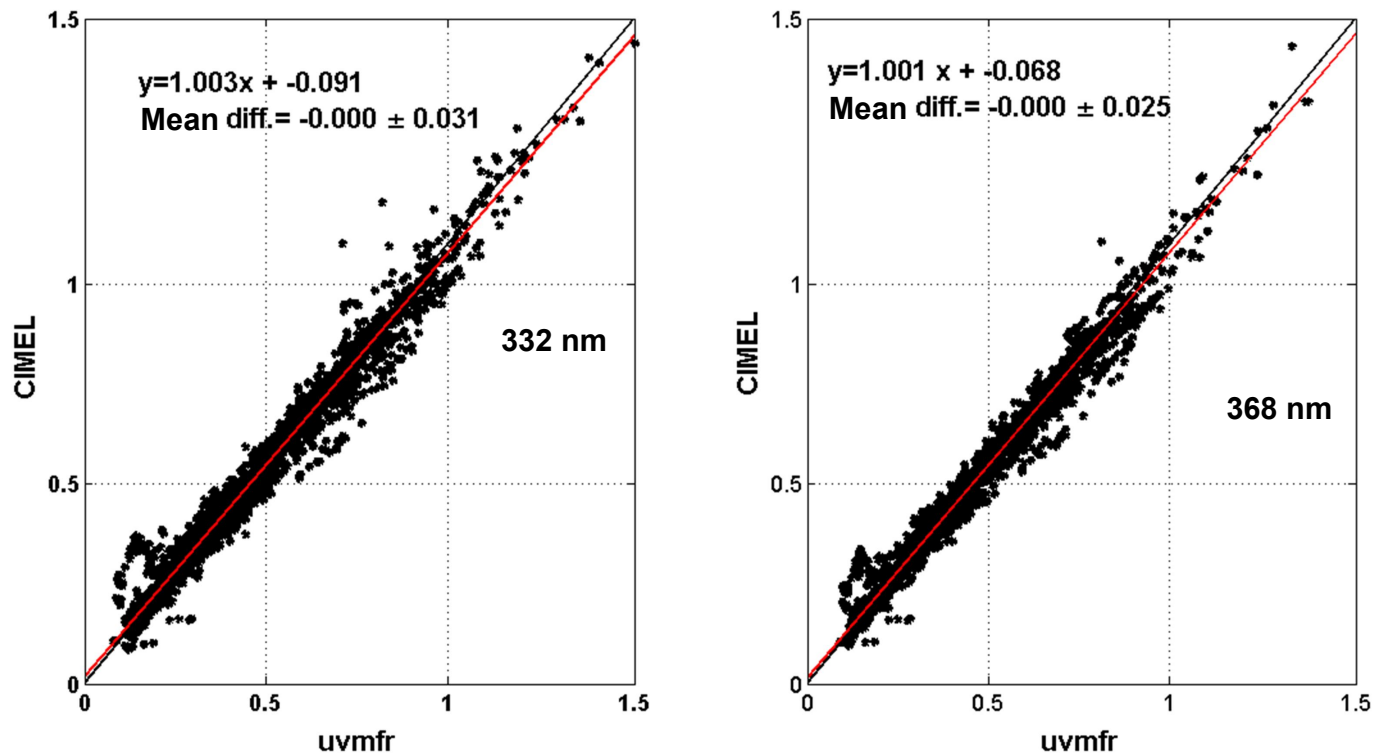

Figure 4. Comparison between the CIMEL and UVMFR retrieved AODs for synchronous measurements, at $332 \mathrm{~nm}$ (left panel) and $368 \mathrm{~nm}$ (right panel).

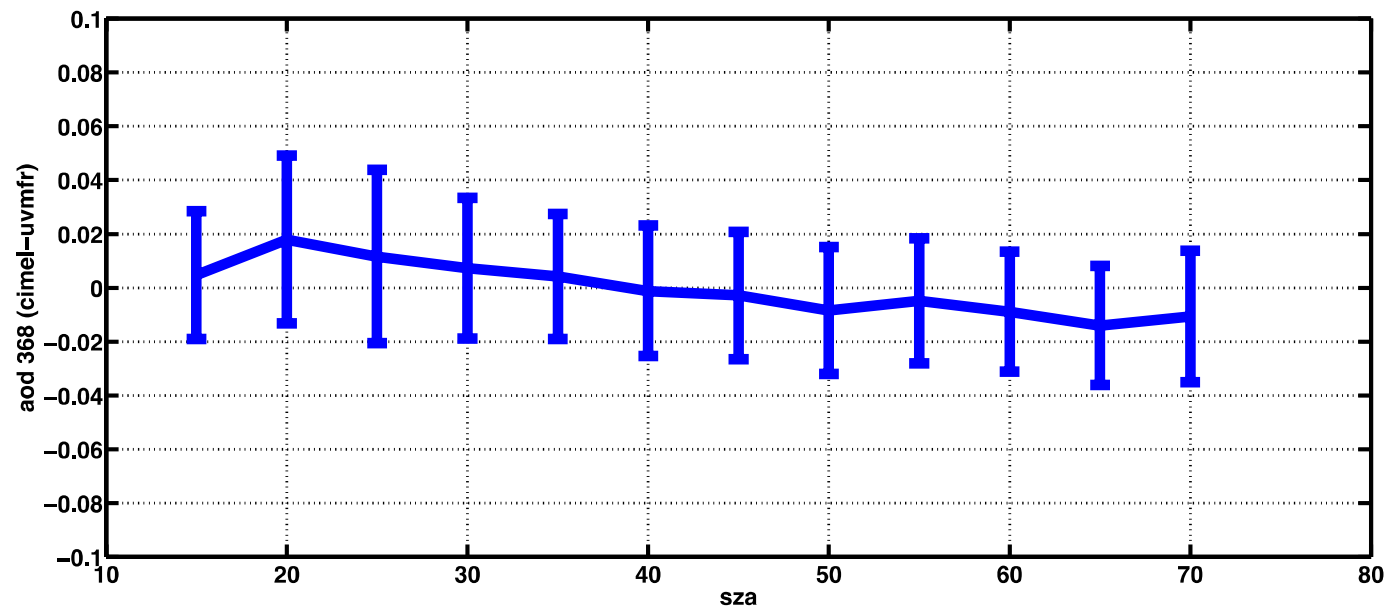

Figure 5. AOD differences between CIMEL and UVMFR at $368 \mathrm{~nm}$ as a function of solar zenith angle.

an enhanced L1.5 SSA dataset with AOD $<0.4$, but with L2 cloud screening, calibrations and quality controls. Data have been compared with UVMFR retrieved SSAs taking into account limitations related to the retrieval uncertainties. Khatri et al. (2016) studied AERONET SSA retrieval uncertainties in order to compare with SKYNET and found that AOD errors introduce the largest variations. They also found that the sky irradiance calibration has a primary role in the uncertainty of the retrieval, and they investigated the influence of surface albedo and sphericity of aerosols, which was found negligible.

Regarding the UVMFR data, the uncertainty of the UVMFR SSA retrieval is mainly related to
- direct to global irradiance measurement uncertainties

- RTM input data accuracy.

Direct to global irradiance measurement uncertainties can result to a range of SSA values rather than a single value, which would produce a close match between the measurement and the RTM DGR outputs. This range broadens at low SZA and high aerosol level cases, as shown in Fig. 6, when the impact of the scattering and absorbing nature of aerosols on solar radiation is higher. The RTM inputs that were used for the SSA LUT construction include also an uncertainty budget (AOD, surface albedo, constant aerosol vertical profile, asymmetry factor). Following the uncertainty analysis of Krotkov et al. (2005b), the total relative uncertainty of the DGR mea- 

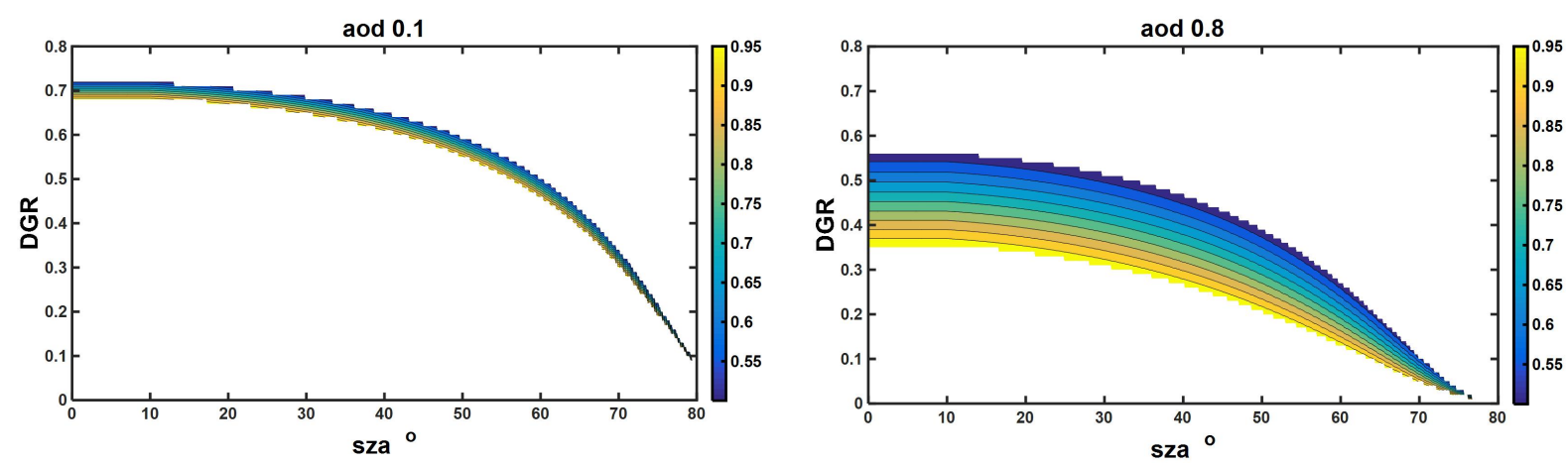

Figure 6. LUT of direct to global ratio at $368 \mathrm{~nm}$, as calculated for AOD 0.1 (left) and 0.8 (right) with respect to SZA ( $g=0.7$ ); color bar represents the SSA values.
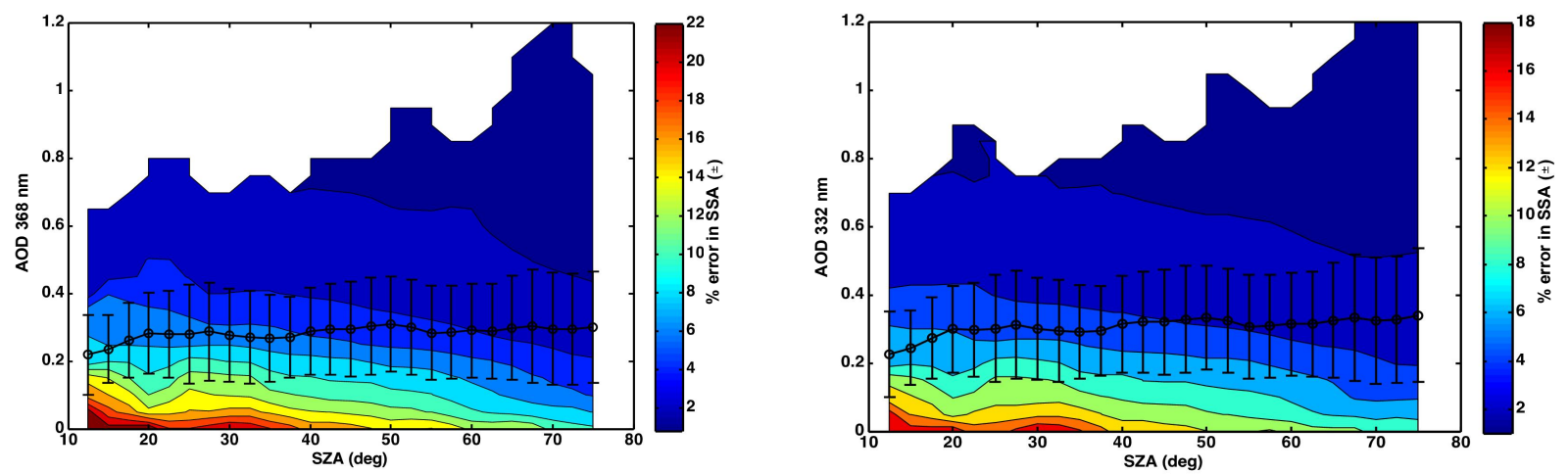

Figure 7. Uncertainty estimate (color) for the SSA retrieval from UVMFR as a function of AOD and SZA at $368 \mathrm{~nm}$ (left panel) and $332 \mathrm{~nm}$ (right panel). This is based on DGR and AOD uncertainties. Superimposed, mean AODs for $2.5^{\circ}$ bins of solar zenith angle are shown.

surement was calculated to be $\pm 3 \%$. AOD absolute uncertainty is considered 0.02 at $368 \mathrm{~nm}$ and 0.04 at $332 \mathrm{~nm}$, following the analysis presented in the previous section. The impact of this on the SSA calculation is directly connected with AOD levels and the SZA. In Fig. 7 we have calculated the UVMFR SSA retrieval uncertainty for different AODs and solar zenith angles, caused by DGR and AOD uncertainty. The DGR and AOD uncertainty ranges were used to calculate the possible SSA range and the expected error. In the Fig. 7, the mean AODs, for each SZA bin (error bars equal to 1 standard deviation) for Athens as measured by the UVMFR at each solar angle, are shown.

\section{SSA retrieval results}

We calculated the SSA at 332 and $368 \mathrm{~nm}$ using 1 min data from the UVMFR. For the period under investigation, we also calculated the daily mean SSAs at these two wavelengths in the UV band and also the mean daily SSAs in the visible band, derived from data provided by the CIMEL (L1.5 data) operating in Athens' AERONET station (Fig. 8).
The $2 \sigma$ variability of SSA during this period is quite high, ranging from $0.75(0.62)$ to $0.98(0.97)$ at $368 \mathrm{~nm}(332 \mathrm{~nm})$, with mean values of $0.90,0.87$ and 0.83 at 440,368 and 332 nm, respectively. In Fig. 9 we have calculated the mean monthly values of SSA at UV wavelengths, accompanied by their respective standard deviation, for the whole period to examine the annual variability. The lowest SSA values were from February to May at both wavelengths, which should be linked to the frequent dust events during this period for the area (Gerasopoulos et al., 2011) as well as the presence of brown carbon. Paraskevopoulou et al. (2014) have found maximum values of organic and elemental carbon, in February and November, in a 5-year (2008-2013) analysis of in situ measurements in Athens. However, most months have similar SSAs, with differences that lie well within the SSA variability of each month. Statistical tests showed that the SSA difference at the two UV wavelengths is statistically significant for all months. Looking at the monthly mean AODs, despite the fact that standard deviations of both SSA and AOD are large, it can be seen that higher AODs are associated with less absorbing aerosol.

The mean diurnal course shows variability of the order of 0.02 to 0.04 , with highest absorption (lowest SSAs) encoun- 


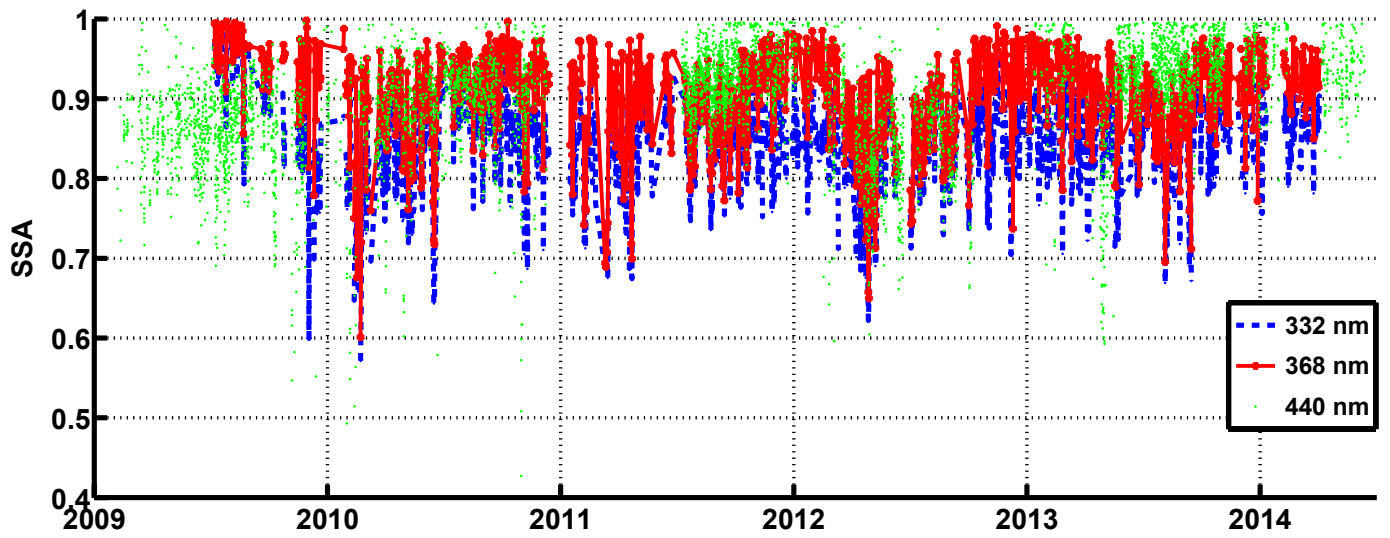

Figure 8. Daily mean SSAs in the UV (UVMFR) at two wavelengths and at $440 \mathrm{~nm}$ (CIMEL) for Athens area.

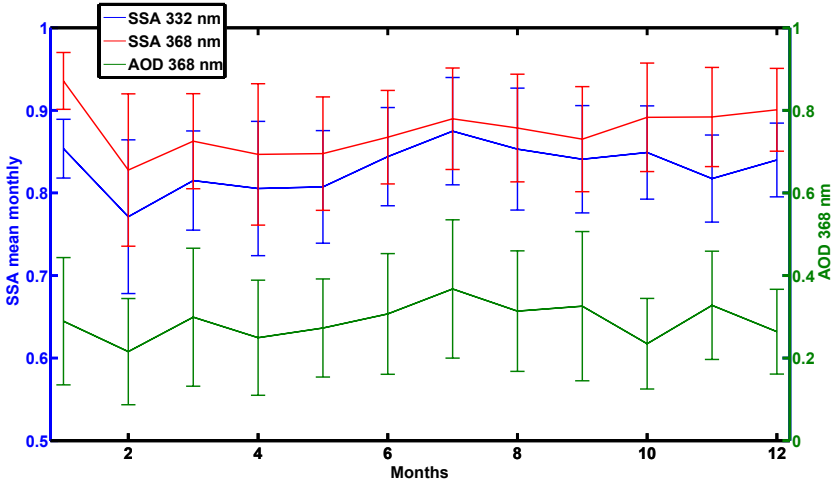

Figure 9. Mean monthly SSAs (left axis) in the UV (UVMFR) at two wavelengths and AOD at $368 \mathrm{~nm}$ from the UVMFR (right axis) for the whole 5-year period in Athens. Error bars represent 1 standard deviation of the mean.

tered $\pm 2 \mathrm{~h}$ around noon (Fig. 10). Similar behavior can also be seen from AERONET retrieved SSAs, with higher values during early morning and late evening. However, the SZA limitation of the AERONET retrieval methodology results to lack of measurement points around noon. To investigate the uncertainty in relation to the UVMFR retrievals, the diurnal pattern was calculated for different SSA bins according to the analysis in the previous section. In general, the daily pattern is clear for each bin and is mirrored by the AERONET inversion retrievals. However, the 1 standard deviation bars are quite large. These bars describe the variability of the SSAs during each hourly bin but also include retrieval uncertainty. We have to note that since no restriction has been introduced for UVMFR SSA retrievals at low AODs, the uncertainty related to these data becomes larger (Fig. 7).

In order to investigate the possible dependence of SSA on AOD, the synchronous UVMFR and CIMEL SSA retrievals plotted against AOD at $440 \mathrm{~nm}$ are shown in Fig. 11. SSA decreases with decreasing optical extinction, although lower AODs are also linked to higher uncertainties of the retrieved

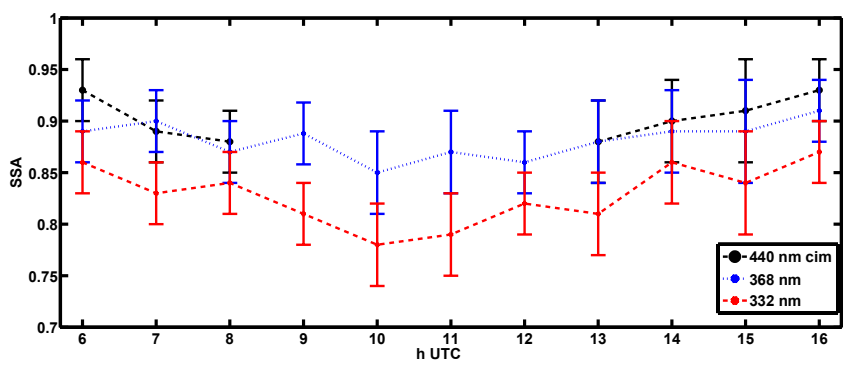

Figure 10. Diurnal patterns of SSA derived from the UVMFR and CIMEL measurements. Mean values per hour are plotted with error bars corresponding to 1 standard deviation. Local time in Athens is $\mathrm{UTC}+2$ (winter) and UTC +3 (summer).

SSA. This behavior probably reflects seasonal changes in the average aerosol composition in Athens. Indeed, the annual cycle of SSA is the same as the AOD annual cycle, having a maximum in summer and a minimum in winter. Studies of the SSA annual variability for other cities such as Ispra, Italy, and Thessaloniki, Greece (Arola et al., 2005; Bais et al., 2005), revealed the same trend, with low SSA values (high absorption) associated with low AOD. It has to be noted that due to low AOD, the uncertainties associated with data obtained from both retrieval techniques (AERONET and UVMFR) are quite high. For higher AOD (>0.6), CIMEL retrievals show an almost constant value of the SSA $\sim 0.92$, while lower values have been retrieved at smaller AODs. Similar results were reported by Krotkov et al. (2005b) when analyzing measurements derived at the AERONET calibration site in Greenbelt, Maryland, USA.

We have performed an analysis of the differences of SSAs between the visible and the UV parts of the spectrum based on aerosol characteristics, using synchronous CIMEL and UVMFR SSA retrievals and an aerosol classification scheme described in detail in Mielonen et al. (2009). In that work, a classification of AERONET data was used in order to derive six aerosol types based on SSA at $440 \mathrm{~nm}$ and the Ångström 


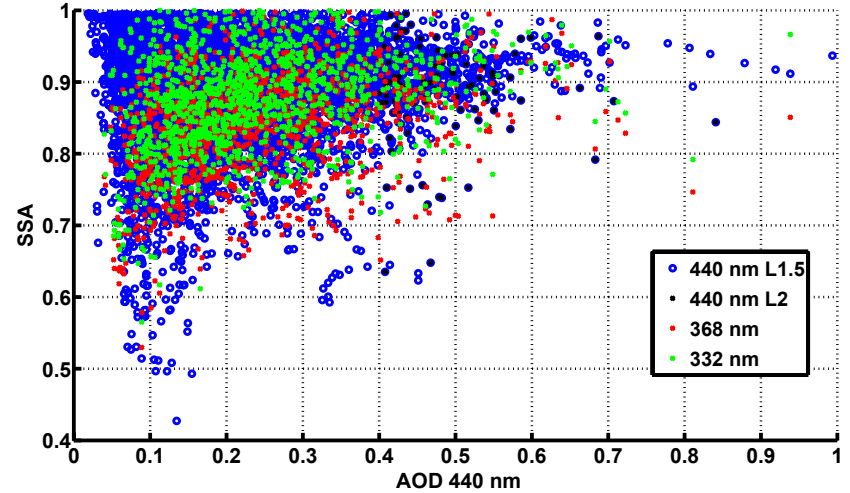

Figure 11. Dependence of the calculated SSA from AOD measurements.

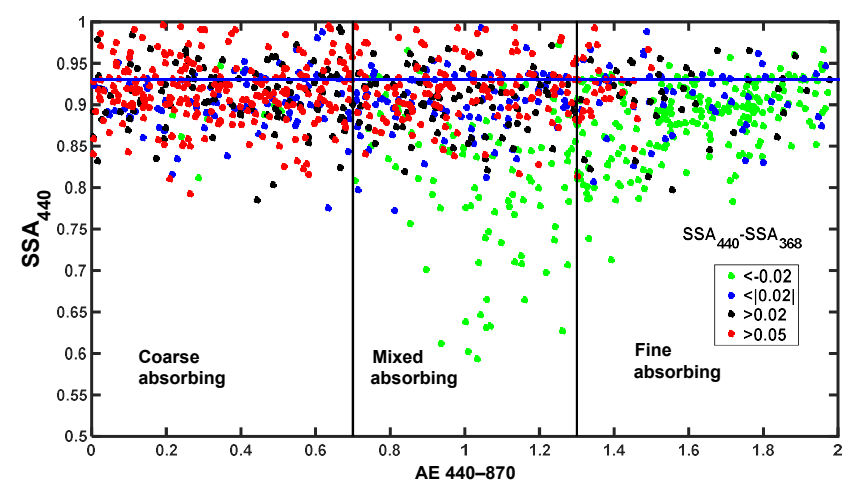

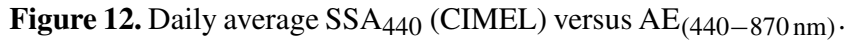
Colors represent different bins of the spectral differences of $\mathrm{SSA}_{440 \mathrm{~nm}}-\mathrm{SSA}_{368 \mathrm{~nm}}$.

exponent (AE) that was derived in the $440-870 \mathrm{~nm}$ wavelength range. Mielonen et al. (2009) used a visualization of this characterization, by plotting AE versus SSA for individual sites, and compared their results with the CALIPSO (Omar et al., 2005) aerosol classification scheme obtaining good agreement. In addition, the difference between SSA at 440 and $1020 \mathrm{~nm}$ (similar to the approach applied by Derimian et al., 2008) was implemented to better distinguish fine absorbing aerosols from coarse. The main idea was to fill this SSA versus AE aerosol-type-related "space" with the differences of SSA $440-\mathrm{SSA}_{368}$ (SSADIFF) to investigate a possible link between SSA wavelength dependence and aerosol type. In Fig. 12 using the Mielonen et al. (2009) aerosol typing approach, we plot SSADIFF for different classes (colored scale) and separate aerosol types by areas in the SSAAE plot. In addition, actual points of $\mathrm{SSA}_{440}$ retrieved from CIMEL are shown in order to categorize the results from Athens site according to the classification scheme.

The results in Fig. 12 show that a mixture of aerosol types is typical for ARSS site in Athens, with SSA440 values spanning in all six sub-spaces. Analyzing the wavelength depen- dency of the SSA, by defining SSADIFF as the difference $\mathrm{SSA}_{440}-\mathrm{SSA}_{368}$, there is evidence that high negative SSADIFF values (that means that the SSA at UV wavelengths is equal or relatively higher than $\mathrm{SSA}_{440}$ ) tend to occur towards high AEs. For these cases (green color in Fig. 11) we observe high absorption cases with AEs around 1, which can be attributed to polluted dust aerosol events. Also the majority of cases which comply with the condition $\mathrm{AE}<0.7$ are found to be of lower SSA at UV by at least $0.05 \mathrm{com}$ pared to SSA440. More specifically, dust cases (mainly during spring) can be identified due to the proximity of Athens to the Saharan desert (Gerasopoulos et al., 2011), explaining this behavior of absorbing aerosols at UV with low AE. Russell et al. (2010) reported results from diverse datasets showing SSA wavelength dependency from the IR down to visible wavelengths. In addition, Bergstrom et al. (2007) presented SSA spectra for dust-containing aerosols campaigns (PRIDE and ACE-Asia), including AERONET measurements at sites that are affected by dust such as Cape Verde, Bahrain (Persian Gulf) and the Solar Village (Saudi Arabia). Both studies concluded that the SSA spectra for AERONET locations were dominated by desert dust decrease with decreasing wavelength. In addition, Russel et al. (2010) reported that SSA spectra for AERONET locations dominated by urbanindustrial and biomass-burning aerosols decrease with increasing wavelength, in line with the results of Bergstrom et al. (2007). Figure 12 also shows that similar SSA values can be found for 440 and $368 \mathrm{~nm}$ and for fine aerosol cases $(\mathrm{AE}>1.4)$.

In order to better understand the potential relative contributions of dust and brown carbon, we applied the method of Schuster et al. (2016) to the AERONET measurements in Athens. This method separates contributions from black carbon, organic carbon, hematite and goethite to the retrieved refractive index at all available wavelengths, even in complex mixtures. Figure 13 shows the fractions of total aerosol volume attributed to these components, as well as the volume fractions, accordingly. It is evident that both brown carbon and mineral dust are likely absorbing components involved in the aerosol mixture in Athens, with brown carbon probably playing the more dominant role. Brown carbon highly absorbs in UV wavelengths and hardly any above $0.7 \mathrm{~nm}$ (Kirchstetter et al., 2004). Brown carbon fraction is higher in October, but it has very large concentrations during the period March-June, which partly explains low SSA values in Fig. 9.

The usefulness of the AE for aerosol extinction is that its value depends primarily on the size of the particles, ranging from a value of 4 for very small particles (Rayleigh scattering) to around 0 for very large particles (such as cloud drops). Various studies (e.g., Bergstrom et al., 2007) have used the Ångström absorption exponent (AAE) to study the aerosol absorption wavelength dependence for different aerosol types and mixtures. AAE is calculated similarly with $\mathrm{AE}$, only using $\mathrm{AOD}^{*}(1-\mathrm{SSA})$ instead of AOD. As the ab- 

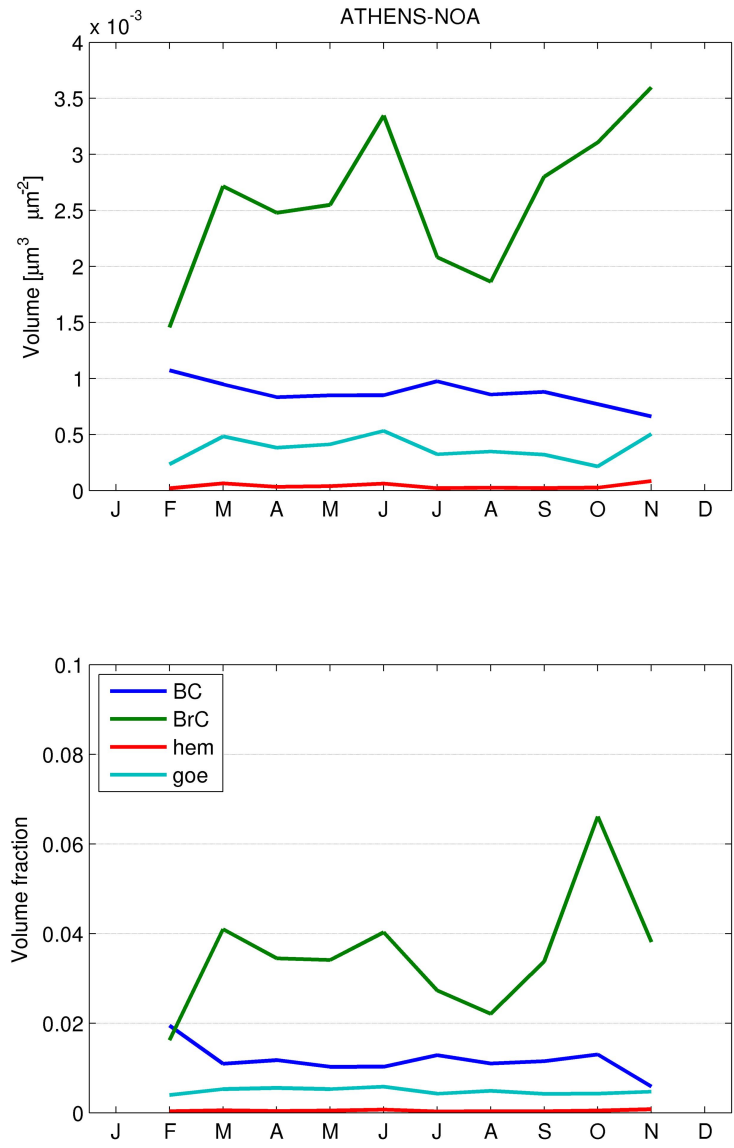

Figure 13. Total volume (in the upper plot) and volume fraction (in the lower plot) of absorbing aerosol components, as inferred from the method of Schuster et al. (2016). The retrieval gives the fractions for fine and coarse mode separately and here the contributions are shown as mode-weighted median value.

sorption AOD is a relatively smooth decreasing function with wavelength, it can be approximated by a power law wavelength dependence via the AAE, which is defined as the negative of the slope of the absorption on a $\log -\log$ plot. The measurements of $\mathrm{AAE}_{(440-870)}$ are found to lie between 0.9 and $1.5(2 \sigma)$, in accordance with the results of Bergstrom et al. (2007). AAE $_{(332-440)}$ in the UV range is very different from that in the visible, with values ranging from 1.4 to 5 $(2 \sigma)$. A direct comparison reveals that for the aerosol composition features of Athens, the AAE values are usually up to 4 times higher in the UV range than in the visible. This is due to the combination of the enhanced absorption (lower SSAs) that has been found in the UV with the higher AODs in this wavelength band.

Finally, we have calculated mean CIMEL SSA values for all four retrieved wavelengths (440, 673, 870 and $1020 \mathrm{~nm})$ and for the whole period under study, and synchronous (5 min SSA averaged around the CIMEL measurement time) UVMFR SSAs at the UV (332 and $368 \mathrm{~nm}$ ). The results are

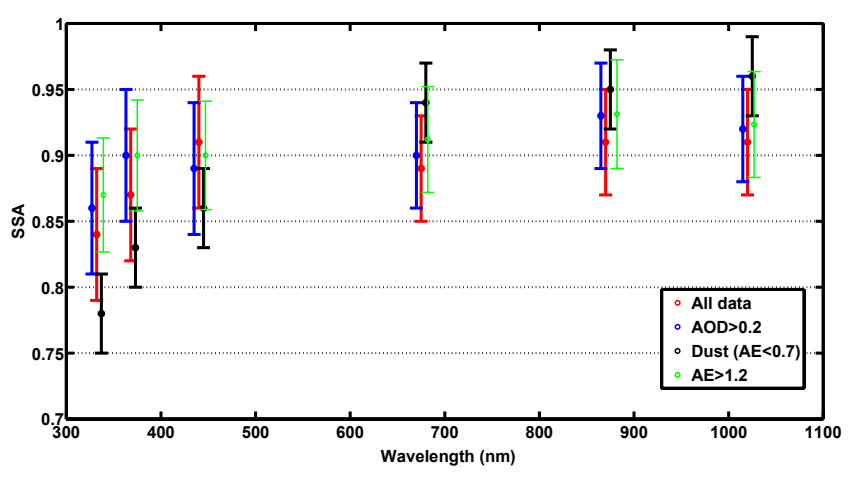

Figure 14. Wavelength dependence of SSA from synchronous CIMEL and UVMFR measurements. Blue points represent all data points, red points are data retrievals with $\mathrm{AOD}>0.2$, green points are data with $\mathrm{AE}>1.2$ and black points are data only dust aerosol cases. Vertical bars represent 1 standard deviation of the calculated mean.

shown in Fig. 14 with error bars at $1 \sigma$. The datasets of the SSA retrievals are separated into four cases: (a) all points (CIMEL L1.5 and all synchronous UVMFR data), (b) measurements retrieved with $\mathrm{AOD}>0.2$ (reduced uncertainty), (c) SSA retrievals for $\mathrm{AE}_{340-440}<0.7$ to identify dust events and (d) cases with $\mathrm{AE}>1.2$ to distinguish the fine mode cases. While for all cases the calculated standard deviation is quite high $(\geq 0.05)$, there is a systematic SSA decrease in the UV range. Mean differences of 0.07 and 0.02 are found when comparing SSA at the visible range and SSA at 332 and $368 \mathrm{~nm}$, respectively. Dust cases, in particular, show a spectral decrease in SSA with decreasing wavelength, from 1022 (CIMEL) down to $332 \mathrm{~nm}$ (UVMFR). Fine mode cases show smaller spectral dependence $\left(\mathrm{SSA}_{440 \mathrm{~nm}}-\mathrm{SSA}_{332 \mathrm{~nm}}<0.03\right)$.

The spectral dependence of the SSA from the visible to the UV wavelengths is in agreement with findings presented by Corr et al. (2009) and Krotkov et al. (2009). The same approach was also applied to Mexico City, where measurements are also influenced by city emissions and blowing dust. Corr et al. (2009) studied the SSA behavior at UV wavelengths and showed that for AOD $>0.1$, SSA varied from 0.78 to 0.80 at 332 and $368 \mathrm{~nm}$, respectively, with enhanced absorption at UV wavelengths relative to VIS, a finding in accordance with these types of aerosols. Krotkov et al. (2009), modifying a UVMFR in order to measure also at $440 \mathrm{~nm}$, found strong SSA wavelength dependence across the blue and near-UV spectral region.

\section{Summary and conclusions}

The advantages of measuring the aerosol absorption (SSA) in the UV with a UVMFR instrument can be summarized as follows:

- AOD, in the UV wavelength range, is higher (for the same aerosol mass) than in the visible spectral range. 
- SSA retrievals with an uncertainty of \pm 0.03 can be derived for SZA $>40^{\circ}$ and with an uncertainty of \pm 0.04 for all SZAs where AOD $>=0.2$.

- SSA retrievals are stable and repeatable over the 5-year period.

We have analyzed a 5-year period of UVMFR and CIMEL measurements performed in Athens, retrieving SSA at visible and UV wavelengths based on the effect of aerosol SSA on the DGR for a given AOD and air mass. Since the CIMEL retrieval algorithm is more accurate for high SZA, the combination of the two instruments allows for higher measurement frequency of SSA and the ability to derive a complete diurnal cycle of aerosol absorption. As a follow-up, the spectral differences of the aerosol absorption properties in the visible and UV wavelength ranges have been investigated, using synchronous CIMEL and UVMFR retrievals. Results of this work confirmed similar results found for Mexico City, Mexico (Corr et al., 2009), Greenbelt, Maryland, USA (Krotkov et al., 2005b), and Rome, Italy (Ialongo et al., 2010), which presented enhanced absorption of aerosols for UV wavelengths.

We have also used the produced dataset to investigate possible effects of aerosol type on the observed SSA wavelength differences. The enhanced UV absorption can be mainly due to either dust or organic aerosol. Our analysis of Athens AERONET measurements suggests that the relative role of absorbing organic aerosol is somewhat more significant than dust. The enhanced aerosol absorption found when comparing UV and visible spectrum results, shows the following:

- We expect a systematic overestimation of modeled solar UV irradiance using SSA from extrapolation from the visible range as an input to RTMs.

- There is a possibility of a decrease in specific days/cases of regional ozone due to enhanced aerosol absorption (Li et al., 2005). For Athens, such a case could be verified only with chemical model results.

- Satellite post-correction results (e.g., Arola et al., 2009), including aerosol absorption effects, have to take into account absorption enhancement in the UV range.

- We expect an overestimation of the UV irradiance (UV index) calculations on cloudless cases under dust and/or brown carbon presence when using SSA values from the visible range. This comes as a combination of the overestimated SSA and the high AODs during such events.

However, the spectral SSA differences that we found are well within the uncertainty of both retrievals, as instrumental effects or absolute calibration uncertainties of sky radiances ( $\sim 5 \%$ for the CIMEL almucantar measurements) might also play an important role in such comparisons. The coincidence of AOD measurements from both instruments, using a single
ETC for various SZA over the extended 5-year period, is a sign that no systematic SZA-dependent factors influence the final SSA results.

The extended SSA dataset significantly improves comparative statistics and provides additional information on the effects of varying background aerosol conditions and higher aerosol absorption compared to that in Washington, DC, where dust aerosol cases are very rare. In conclusion, the combined use of CIMEL sun and sky radiance measurements in the visible with UVMFR total and diffuse irradiance measurements in the UV provides an important advantage for remote measurements of column aerosol absorption over the UV-VIS spectral range.

\section{Data availability}

Data can be accessed through personal communication with S. Kazadzis.

Acknowledgements. Panagiotis Raptis would like to acknowledge the project Aristotelis SOLAR (50561), "Investigation on the factors affecting the solar radiation field in Greece". Vassilis Amiridis, Stelios Kazadzis and Evangelos Gerasopoulos would like to acknowledge the project "European Union's Horizon $2020 \mathrm{Re}$ search and Innovation Programme ACTRIS-2" (grant agreement no. 654109).

Edited by: O. Torres

Reviewed by: N. A. Krotkov and one anonymous referee

\section{References}

Alfaro, S. C., Lafon, S., Rajot, J. L., Formenti, P., Gaudichet, A., and Maillé, M.: Iron oxides and light absorption by pure desert dust: An experimental study, J. Geophys. Res.-Atmos., 109, D08208, doi:10.1029/2003jd004374, 2004.

Amiridis, V., Kafatos, M., Perez, C., Kazadzis, S., Gerasopoulos, E., Mamouri, R. E., Papayannis, A., Kokkalis, P., Giannakaki, E., Basart, S., Daglis, I., and Zerefos, C.: The potential of the synergistic use of passive and active remote sensing measurements for the validation of a regional dust model, Ann. Geophys., 27, 3155-3164, doi:10.5194/angeo-27-3155-2009, 2009.

Arola, A., Kazadzis, S., Krotkov, N., Bais, A., Gröbner, J., and Herman, J. R.: Assessment of TOMS UV bias due to absorbing aerosols, J. Geophys. Res.-Atmos., 110, 1-7, 2005.

Arola, A., Kazadzis, S., Lindfors, A., Krotkov, N., Kujanpaa, J., Tamminen, J., Bais, A., di Sarra, A., Villaplana, J. M., Brogniez, C., Siani, A. M., Janouch, M., Weihs, P., Koskela, T., Kouremeti, N., Meloni, D., Buchard, V., Auriol, F., Ialongo, I., Staneck, M., Simic, S., Webb, A., Smedley, A., and Kinne, S.: A new approach to correct for absorbing aerosols in OMI UV: a preliminary evaluation, Geophys. Res. Lett., 36, L22805, doi:10.1029/2009GL041137, 2009.

Bais, A. F., Kazantzidis, A., Kazadzis, S., Balis, D. S., Zerefos, C. S., and Meleti, C.: Deriving an effective aerosol single scatter- 
ing albedo from spectral surface UV irradiance measurements, Atmos. Environ., 39, 1093-1102, 2005.

Bais, A. F., McKenzie, R. L., Bernhard, G., Aucamp, P. J., Ilyas, M., Madronich, S., and Tourpali, K.: Ozone depletion and climate change: impacts on UV radiation, Photochemical \& Photobiological Sciences?: Official Journal of the European Photochemistry Association and the European Society for Photobiology, doi:10.1039/c4pp90032d, 2014.

Balis, D. S., Amiridis, V., Zerefos, C., Kazantzidis, A., Kazadzis, S., Bais, A. F., Meleti, C., Gerasopoulos, E., Papayannis, A., Matthias, V., Dier, H., and Andreae, M. O.: Study of the effect of different type of aerosols on UV-B radiation from measurements during EARLINET, Atmos. Chem. Phys., 4, 307-321, doi:10.5194/acp-4-307-2004, 2004.

Barnard, J. C., Volkamer, R., and Kassianov, E. I.: Estimation of the mass absorption cross section of the organic carbon component of aerosols in the Mexico City Metropolitan Area, Atmos. Chem. Phys., 8, 6665-6679, doi:10.5194/acp-8-6665-2008, 2008.

Bergstrom, R. W., Pilewskie, P., Schmid, B., and Russell, P. B.: Estimates of the spectral aerosol single scattering albedo and aerosol radiative effects during SAFARI 2000, J. Geophys. Res.-Atmos., 108, 8474, doi:10.1029/2002JD002435, 2003.

Bergstrom, R. W., Pilewskie, P., Russell, P. B., Redemann, J., Bond, T. C., Quinn, P. K., and Sierau, B.: Spectral absorption properties of atmospheric aerosols, Atmos. Chem. Phys., 7, 5937-5943, doi:10.5194/acp-7-5937-2007, 2007.

Bornman, J. F. and Teramura, A. H.: Effects of ultraviolet-B radiation on terrestrial plants, in: Environmental UV-Photobiology, edited by: Young, A. R., Björn, L. O., Moan, J., and Nultsch, W., Plenum Press, New York, 427-471, 1993.

Castro, T., Madronich, S., Rivale, S., Muhlia, A., and Mar, B.: The influence of aerosols on photochemical smog in Mexico City, Atmos. Environ., 35, 1765-1772, 2001.

Corr, C. A., Krotkov, N., Madronich, S., Slusser, J. R., Holben, B., Gao, W., Flynn, J., Lefer, B., and Kreidenweis, S. M.: Retrieval of aerosol single scattering albedo at ultraviolet wavelengths at the T1 site during MILAGRO, Atmos. Chem. Phys., 9, 58135827, doi:10.5194/acp-9-5813-2009, 2009.

den Outer, P. N., Slaper, H., and Tax, R. B.: UV radiation in the Netherlands: Assessing long-term variability and trends in relation to ozone and clouds, J. Geophys. Res., 110, D02203, doi:10.1029/2004jd004824, 2005.

Derimian, Y., Léon, J.-F., Dubovik, O., Chiapello, I., Tanré, D., Sinyuk, A., Auriol, F., Podvin, T., Brogniez, G., and Holben, B. N.: Radiative properties of aerosol mixture observed during the dry season 2006 over M'Bour, Senegal (African Monsoon Multidisciplinary Analysis campaign), J. Geophys. Res., 113, D00C09, doi:10.1029/2008JD009904, 2008.

Dickerson, R. R., Kondragunta, S., Stenchikov, G., Civerolo, K. L., Doddridge, B. G., and Holben, B. N.: The impact of aerosols on solar ultraviolet radiation and photochemical smog, Science, 278, 827-830, 1997.

Diffey, B. L.: Solar Ultraviolet-Radiation Effects On BiologicalSystems, Phys. Med. Biol., 36, 299-328, 1991.

Dubovik, O. and King, M. D.: A flexible inversion algorithm for retrieval of aerosol optical properties from Sun and sky radiance measurements, J. Geophys. Res.-Atmos., 105, 20673-20696, 2000.
Dubovik, O., Holben, B. N., Lapyonok, T., Sinyuk, A., Mishchenko, M. I., Yang, P., and Slutsker, I.: Non-spherical aerosol retrieval method employing light scattering by spheroids, Geophys. Res. Lett., 29, 1415, doi:10.1029/2001GL014506, 2002.

Eck, T. F., Holben, B. N., Slutsker, I., and Setzer, A.: Measurements of irradiance attenuation and estimation of aerosol single scattering albedo for biomass burning aerosols in Amazonia, J. Geophys. Res., 103, 31865-31878, 1998.

Eck, T. F., Holben, Â. N., Reid, J. S., Dubovik, Î., Smirnov, A., O'Neill, N. T., Slutsker, I., and Kinne, S.: Wavelength dependence of the optical depth of biomass burning, urban and desert dust aerosols, J. Geophys. Res., 104, 31333-31350, 1999.

Eck, T. F., Holben, B. N., Ward, D. E., Mukelabai, M. M., Dubovik, O., Smirnov, A., Schafer, J. S., Hsu, N. C., Piketh, S. J., Queface, A., and Roux, J. L.: Variability of biomass burning aerosol optical characteristics in southern Africa during the SAFARI 2000 dry season campaign and a comparison of single scattering albedo estimates from radiometric measurements, J. Geophys. Res.-Atmos., 108, 2156-2202, doi:10.1029/2002JD002321, 2003.

Elminir, H. K.: Sensitivity of ultraviolet solar radiation to anthropogenic air pollutants and weather conditions, Atmos. Res., 84, 250-264, 2007.

Flores, J. M., Washenfelder, R. A., Adler, G., Lee, H. J., Segev, L., Laskin, J., Laskin, A., Nizkorodov, S. A., Brown, S. S., and Rudich, Y.: Complex refractive indices in the near-ultraviolet spectral region of biogenic secondary organic aerosol aged with ammonia, Phys. Chem. Chem. Phys., 16, 10629-10642, doi:10.1039/C4cp01009d, 2014.

Gerasopoulos, E., Kokkalis, P., Amiridis, V., Liakakou, E., Perez, C., Haustein, K., Eleftheratos, K., Andreae, M. O., Andreae, T. W., and Zerefos, C. S.: Dust specific extinction cross-sections over the Eastern Mediterranean using the BSC-DREAM model and sun photometer data: the case of urban environments, Ann. Geophys., 27, 2903-2912, doi:10.5194/angeo-27-29032009, 2009.

Goering, C. D., L'Ecuyer, T. S., Stephens, G. L., Slusser, J. R., Scott, G., Davis, J., Barnard, J. C., and Madronich, S.: Simultaneous retrievals of column ozone and aerosol optical properties from direct and diffuse solar irradiance measurements, J. Geophys. Res., 110, D05204, doi:10.1029/2004jd005330, 2005.

Harrison, L., Michalsky, J., and Berndt, J.: Automated Multi-Filter Rotating Shadowband Radiometer: An instrument for Optical Depth and Radiation Measurements, Appl. Opt., 33, 5118-5125, 1994.

Gröbner, J., Kouremeti, N., and Rembges, D.: A systematic comparison of solar UV radiation spectra with radiative transfer calculations, 8th European Symposium on Physico-Chemical Behaviour of Air Pollutants, A Changing Atmosphere EC, ORA/POST 62172, 2001.

Herman, B. M., Browning, S. R., and DeLuisi, J. J.: Determination of the effective imaginary term of the complex refractive index of atmospheric dust by remote sensing: the diffuse-direct radiation method, J. Atmos. Sci., 32, 918-925, 1975.

Holben, B. N., Eck, T. F., Slutsker, I., Tanré, D., Buis, J. P., Setzer, A., Vermote, E., Reagan, J. A., Kaufman, Y. J., Nakajima, T., Lavenu, F., Jankowiak, I., and Smirnov, A.: AERONET-A Federated Instrument Network and Data Archive for Aerosol Characterization, Remote Sens. Environ., 66, 1-16, 1998. 
Ialongo, I., Buchard, V., Brogniez, C., Casale, G. R., and Siani, A. M.: Aerosol Single Scattering Albedo retrieval in the UV range: an application to OMI satellite validation, Atmos. Chem. Phys., 10, 331-340, doi:10.5194/acp-10-331-2010, 2010.

IPCC: Climate Change 2013: The Physical Science Basis. Contribution of Working Group I to the Fifth Assessment Report of the Intergovernmental Panel on Climate Change, edited by: Stocker, T. F., Qin, D., Plattner, G. K., Tignor, M., Allen, S. K., Boschung, J., Nauels, A., Xia, Y., Bex, V., and Midgley, P. M., Cambridge University Press, Cambridge, United Kingdom and New York, NY, USA, 1535 pp., doi:10.1017/CBO9781107415324, 2013.

Jacobson, M. Z.: Isolating nitrated and aromatic aerosols and nitrated aromatic gases as sources of ultraviolet light absorption, J. Geophys. Res., 104, 3527-3542, 1999.

Jethva, H. and Torres, O.: Satellite-based evidence of wavelengthdependent aerosol absorption in biomass burning smoke inferred from Ozone Monitoring Instrument, Atmos. Chem. Phys., 11, 10541-10551, doi:10.5194/acp-11-10541-2011, 2011.

Jethva, H., Torres, O., and Ahn, C.: Global assessment of OMI aerosol single-scattering albedo using ground-based AERONET inversion, J. Geophys. Res.-Atmos., 119, 90209040, doi:10.1002/2014JD021672, 2014.

Kassianov, E. I., Barnard, J. C., and Ackerman, T. P.: Retrieval of aerosol microphysical properties using surface MultiFilter Rotating Shadowband Radiometer (MFRSR) data: Modeling and observations, J. Geophys. Res.-Atmos., 110, 1-12, doi:10.1029/2004jd005337, 2005.

Kazadzis, S., Bais, A., Balis, D., Kouremeti, N., Zempila, M., Arola, A., Giannakaki, E., Amiridis, V., and Kazantzidis, A.: Spatial and temporal UV irradiance and aerosol variability within the area of an OMI satellite pixel, Atmos. Chem. Phys., 9, 4593-4601, doi:10.5194/acp-9-4593-2009, 2009.

Kazadzis, S., Gröbner, J., Arola, A., and Amiridis, V.: The effect of the global UV irradiance measurement accuracy on the single scattering albedo retrieval, Atmos. Meas. Tech., 3, 1029-1037, doi:10.5194/amt-3-1029-2010, 2010.

Khatri, P., Takamura, T., Nakajima, T., Estellés, V., Irie, H., Kuze, H., Campanelli, M., Sinyuk, A., Lee, S.-M., Sohn, B. J., Padhithurai, G., Kim, S.-W., Yoon, S. C., Lozano, J. A. M., Hashimoto, M., Devara, P. C. S., and Manago, N.: Factors for inconsistent aerosol single scattering albedo between SKYNET and AERONET, J. Geophys. Res.-Atmos., 121, 18591877, doi:10.1002/2015JD023976, 2016.

Kirchstetter, T. W., Novakov, T., and Hobbs, P. V.: Evidence that the spectral dependence of light absorption by aerosols is affected by organic carbon, J. Geophys. Res., 109, D21208, doi:10.1029/2004JD004999, 2004.

King, M.: Determination of the ground albedo and the index of absorption of atmospheric particles by remote sensing, Part II: Application, J. Atmos. Sci., 36, 1072-1083, 1979.

King, M. and Herman, B. M.: Determination of the ground albedo and the index of absorption of atmospheric particles by remote sensing, Part I: Theory, J. Atmos. Sci., 36, 163-173, 1979.

Krotkov, N. A., Bhartia, P. K., Herman, J. R., Fioletov, V., and Kerr, J.: Satellite estimation of spectral surface UV irradiance in the presence of tropospheric aerosols 1, Cloud-free case, J. Geophys. Res.-Atmos., 103, 8779-8793, 1998.

Krotkov, N. A., Bhartia, P. K., Herman, J., Slusser, J., Labow, G., Scott, G., Janson, G., Eck, T. F., and Holben, B.: Aerosol ultra- violet absorption experiment (2002 to 2004), part 1: Ultraviolet multifilter rotating shadowband radiometer calibration and intercomparison with CIMEL sunphotometers, Opt. Eng., 44, 1-17, 2005a.

Krotkov, N. A., Bhartia, P. K., Herman, J., Slusser, J., Scott, G., Labow, G., Vasilkov, A. P., Eck, T. F., Dubovik, O., and Holben, B. N.: Aerosol ultraviolet absorption experiment (2002 to 2004), part 2: Absorption optical thickness, refractive index, and single scattering albedo, Opt. Eng., 44, 1-17, 2005b.

Krotkov, N. A., Labow, G., Slusser, H., Tree, R., Janson, G., Eck, D. T., and Holben, B.: Aerosol column absorption measurements using co-located UV-MFRSR and AERONET CIMEL instruments, Proc. SPIE 7462, Ultraviolet and Visible Ground and Spacebased Measurements, Trace Gases, Aerosol. Effect., VI, 746205; doi:10.1117/12.826880, 2009

Krzyścin, J. W. and Puchalski, S.: Aerosol impact on the surface UV radiation from the ground-based measurements taken at Belsk, Poland, 1980-1996, J. Geophys. Res., 103, 16175-16181, doi:10.1029/98JD00899, 1998.

Kudo, R., Uchiyama, A., Yamazaki, A., Kobayashi, E., and Nishizawa, T.: Retrieval of aerosol single-scattering properties from diffuse and direct irradiances: Numerical studies, J. Geophys. Res., 113, D09204, 10.1029/2007jd009239, 2008.

Li, G., Zhang, R., Fan, J., and Tie, X.: Impacts of black carbon aerosol on photolysis and ozone, J. Geophys. Res., 110, D23206, doi:10.1029/2005JD005898, 2005.

Liu S., Aiken, A. C., Gorkowski, K., Dubey, M. K., Cappa, C. D., Williams, L. R., Herndon, S. C., Massoli, P., Fortner, E. C., Chhabra, P. S., Brooks, W. A., Onasch, T. B., Jayne, J. T., Worsnop, D. R., China, S., Sharma, N., Mazzoleni, C., Xu, L., Ng, N. L., Liu, D., Allan, J. D., Lee, J. D., Fleming, Z. L., Mohr, C., Zotter, P., Szidat, S., and Prévôt, A. S. H.: Enhanced light absorption by mixed source black and brown carbon particles in UK winter, Nat. Commun., 6, 8435, doi:10.1038/ncomms9435, 2015.

Mayer, B. and Kylling, A.: Technical note: The libRadtran software package for radiative transfer calculations - description and examples of use, Atmos. Chem. Phys., 5, 1855-1877, doi:10.5194/acp-5-1855-2005, 2005.

Medina, R., Fitzgerald, R. M., and Min, Q.: Retrieval of the single scattering albedo in the El Paso-Juarez Airshed using the TUV model and a UV-MFRSR radiometer, Atmos. Environ., 46, 430440, doi:10.1016/j.atmosenv.2011.09.028, 2012.

Meleti, C., Bais, A. F., Kazadzis, S., Kouremeti, N., Garane, K., and Zerefos, C.: Factors affecting solar ultraviolet irradiance measured since 1990 at Thessaloniki, Greece, Int. J. Remote Sens., 30, 4167-4179, 2009.

Mielonen, T., Arola, A., Komppula, M., Kukkonen, J., Koskinen, J., de Leeuw, G., and Lehtinen, K. E. J.: Comparison of CALIOP level 2 aerosol subtypes to aerosol types derived from AERONET inversion data, Geophys. Res. Lett., 36, L18804, doi:10.1029/2009g1039609, 2009.

Mok, J., Krotkov, N. A., Arola, A., Torres, O., Jethva, H., Andrade, M., Labow, G., Eck, T. F., Li, Z., Dickerson, R. R., Stenchikov, G. L., Osipov, S., and Ren, X.: Impacts of brown carbon from biomass burning on surface UV and ozone photochemistry in the Amazon Basin, Nat. Sci. Rep., 6, 36940, doi:10.1038/srep36940, 2016. 
Moosmüller, H., Engelbrecht, J. P., Skiba, M., Frey, G., Chakrabarty, R. K., and Arnott, W. P.: Single scattering albedo of fine mineral dust aerosols controlled by iron concentration, J. Geophys. Res., 117, D11210, doi:10.1029/2011JD016909, 2012.

Müller, D., Wandinger, U., and Ansmann, A.: Microphysical particle parameters from extinction and backscatter lidar data by inversion with regularization: Simulation, Appl. Opt., 38, 23582368, 1999.

Nakajima, T., Tonna, G., Rao, R., Boi, P., Kaufman, Y., and Holben, B.: Use of sky brightness measurements from ground for remote sensing of particulate polydispersions, Appl. Opt., 35, 2672-2686, 1996.

Nikitidou, E., Kazantzidis, A., De Bock, V., and De Backer, H.: The aerosol forcing efficiency in the UV region and the estimation of single scattering albedo at a typical West European site, 69, 313-320, Atmos. Environ., doi:10.1016/j.atmosenv.2012.12.035, 2013.

Omar, A. H., Won, J. G., Winker, D. M., Yoon, S. C., Dubovik, O., and McCormick, M. P.: Development of global aerosol models using cluster analysis of Aerosol Robotic Network (AERONET) measurements, J. Geophys. Res.-Atmos., 110, D10S14, doi:10.1029/2004JD004874, 2005.

Paraskevopoulou, D., Liakakou, E., Gerasopoulos, E., Theodosi, C., and Mihalopoulos, N.: Long-term characterization of organic and elemental carbon in the $\mathrm{PM}_{2.5}$ fraction: the case of Athens, Greece, Atmos. Chem. Phys., 14, 13313-13325, doi:10.5194/acp-14-13313-2014, 2014.

Paur, R. J. and Bass, A. M.: The Ultraviolet Cross-Sections of Ozone: II, Results and Temperature Dependence, in: Atmospheric Ozone, edited by: Zerefos, C. S. and Ghazi, A., Dordrecht, Springer, 611-616, 1985

Petters, J. L., Saxena, V. K., Slusser, J. R., Wenny, B. N., and Madronich, S.: Aerosol single scattering albedo retrieved from measurements of surface UV irradiance and a radiative transfer model, J. Geophys. Res., 108, D94288, doi:10.1029/2002JD002360, 2003.

Reuder, J. and Schwander, H.: Aerosol effects on UV radiation in nonurban regions, J. Geophys. Res., 104, 4065-4077, doi:10.1029/1998JD200072, 1999.

Russell, P. B., Bergstrom, R. W., Shinozuka, Y., Clarke, A. D., DeCarlo, P. F., Jimenez, J. L., Livingston, J. M., Redemann, J., Dubovik, O., and Strawa, A.: Absorption Angstrom Exponent in AERONET and related data as an indicator of aerosol composition, Atmos. Chem. Phys., 10, 1155-1169, doi:10.5194/acp-101155-2010, 2010.

Schuster, G. L., Dubovik, O., and Arola, A.: Remote sensing of soot carbon - Part 1: Distinguishing different absorbing aerosol species, Atmos. Chem. Phys., 16, 1565-1585, doi:10.5194/acp16-1565-2016, 2016.

Smirnov, A., Holben, B. N., Eck, T. F., Dubovik, O., and Slutsker, I.: Cloud-screening and quality control algorithms for the AERONET database, Remote Sens. Environ., 73, 337-349, 2000 .
Tanskanen, A., Lindfors, A., Määttä, A., Krotkov, N., Herman, J., Kaurola, J., Koskela, T., Lakkala, K., Fioletov, V., Bernhard, G., McKenzie, R., Kondo, Y., O’Neill, M., Slaper, H., den Outer, P., Bais, A. F., and Tamminen, J.: Validation of daily erythemal doses from Ozone Monitoring Instrument with ground-based UV measurement data, Validation of daily erythemal doses from ozone monitoring instrument with groundbased UV measurement data, J. Geophys. Res., 112, D24S44, doi:10.1029/2007JD008830, 2007.

Taylor, T. E., L'Ecuyer, T. S., Slusser, J. R., Stephens, G. L., and Goering, C. D.: An operational retrieval algorithm for determining aerosol optical properties in the ultraviolet, J. Geophys. Res., 113, D03201, doi:10.1029/2007jd008661, 2008.

Torres, O., Tanskanen, A., Veihelmann, B., Ahn, C., Braak, R., Bhartia, P. K., Veefkind, P., and Levelt, P.: Aerosols and surface UV products from Ozone Monitoring Instrument observations: An overview, J. Geophys. Res., 112, D24S47, doi:10.1029/2007JD008809, 2007.

UNEP: Environmental effects of ozone depletion and its interactions with climate change: 2002 assessment, executive summary, Photochem. Photobio. S., 2, 1-4, 2003.

UNEP, Van der Leun, J. C., Tang, X., and Tevini, M.: Environmental effects of ozone depletion: 1998 assessment, J. Photochem. Photobiol. B, 46, 28-53, doi:10.1016/s1011-1344(98)00195-x, 1998.

UNEP, Van Der Leun, J., Bornman, J. F., and Tang, X.: Environmental effects of ozone depletion and its interactions with climate change: 2006 Assessment, Photochem. Photobiol. Sci., 6, 209-209, doi:10.1039/B700016B, 2007.

Van Weele, M., Martin, T. J., Blumthaler, M., Brogniez, C., Den Outer, P. N., Engelsen, O., Lenoble, J., Mayer, B., Pfister, G., Ruggaber, A., Walravens, B., Weihs, P., Gardiner, B. G., Gillotay, D., Haferl, D., Kylling, A., Seckmeyer, G., and Wauben, W. M. F.: From model intercomparison toward benchmark UV spectra for six real atmospheric cases, J. Geophys. Res.-Atmos., 105, 4915-4925, 2000.

WMO: Scientific Assessment of Ozone Depletion: 2002, Global Ozone Research and Monitoring Project - Report No. 47, Geneva, Switzerland, 498 pp., 2003.

Yu, H., Kaufman, Y. J., Chin, M., Feingold, G., Remer, L. A., Anderson, T. L., Balkanski, Y., Bellouin, N., Boucher, O., Christopher, S., DeCola, P., Kahn, R., Koch, D., Loeb, N., Reddy, M. S., Schulz, M., Takemura, T., and Zhou, M.: A review of measurement-based assessments of the aerosol direct radiative effect and forcing, Atmos. Chem. Phys., 6, 613-666, doi:10.5194/acp-6-613-2006, 2006.

Zerefos, C. S., Tourpali, K., Eleftheratos, K., Kazadzis, S., Meleti, C., Feister, U., Koskela, T., and Heikkilä, A.: Evidence of a possible turning point in solar UV-B over Canada, Europe and Japan, Atmos. Chem. Phys., 12, 2469-2477, doi:10.5194/acp-12-24692012, 2012. 